\title{
Prevalence and Satisfaction of Discharged Patients Who Recall Interacting with a Pharmacist During a Hospital Stay
}

\author{
Lori Romonko Slack and Lesley Ing
}

\begin{abstract}
Background: To enhance the quality of patient care, the former Calgary Health Region (now part of Alberta Health Services) works continuously to improve pharmacy clinical services and to plan and implement new programs and services. Patient satisfaction is an important indicator of patients' perception of the value of services provided.

Objectives: To determine the baseline prevalence of patients admitted to the former Calgary Health Region with complex and high-risk medication needs who recalled speaking to a pharmacist during their hospital stay and their reported satisfaction with those interactions.

Methods: A retrospective cross-sectional study was conducted by means of a telephone survey of patients shortly after discharge. Patients were asked whether they recalled speaking with a pharmacist during their last stay in the hospital. Patients who recalled such interactions were asked to rate pharmacy services on a 5-point scale.

Results: Of 1200 patients who were discharged from hospital in June 2007 and who were contacted by telephone 2 months later, 400 patients agreed to participate in the survey; 3 of these patients were subsequently excluded. Of the 397 respondents included in the analysis, $83(20.9 \%)$ recalled speaking to a pharmacist. Most of these rated the interaction favourably, with an average satisfaction rating of 4.4 out of 5 .

Conclusions: The Pharmacy Department of the former Calgary Health Region now has baseline frequency and satisfaction data for this indicator of service value, which can be used as comparators for future assessments of service value.
\end{abstract}

Key words: patient satisfaction, pharmacist clinical coverage, clinical pharmacy services

\section{RÉSUMÉ}

Contexte : Pour améliorer la qualité des soins aux patients, l'ex-Régie régionale de la santé de Calgary (qui fait maintenant partie des Services de santé de l'Alberta) travaillait sans relâche pour améliorer les services de pharmacie clinique ainsi que planifier et mettre en œuvre de nouveaux programmes et services. La satisfaction des patients est un important indicateur de la perception qu'ont les patients de la valeur des services qui leur sont fournis.

Objectifs : Déterminer le nombre de patients admis dans l'un des établissements de l'ex-Régie régionale de la santé de Calgary, ayant des besoins en médicaments complexes et à haut risque, qui se souviennent avoir parlé à un pharmacien pendant leur hospitalisation, ainsi que leur degré de satisfaction déclaré relativement à ces interactions.

Méthodes : Une étude rétrospective transversale a été menée au moyen d'un sondage téléphonique peu de temps après le congé des patients. On leur demandait s'ils se souvenaient avoir parlé à un pharmacien durant leur séjour le plus récent à l'hôpital. On demandait alors aux patients qui s'en souvenaient d'évaluer les services de pharmacie sur une échelle de 5 points.

Résultats : Des 1200 patients qui ont été congédiés de l'hôpital en juin 2007 et qui ont été joints par téléphone 2 mois plus tard, 400 ont répondu au sondage; 3 d'entre eux ont par la suite été exclus. Des 397 répondants inclus dans l'analyse, $83(20,9 \%)$ se souvenaient avoir parlé à un pharmacien. La plupart de ces derniers ont évalué leur interaction comme étant positive, avec une cote moyenne de satisfaction de 4,4 sur 5 .

Conclusions : Le Service de pharmacie de l'ex-Régie régionale de la santé de Calgary possède maintenant des données de référence sur la fréquence et la satisfaction relativement à cet indicateur de la valeur du service, qu'on peut utiliser comme éléments de comparaison pour les évaluations futures de la valeur du service.

Mots clés : satisfaction des patients, présence clinique des pharmaciens, services de pharmacie clinique

[Traduction par l'éditeur] 


\section{INTRODUCTION}

$\Lambda$ s the profession of pharmacy expands to encompass new

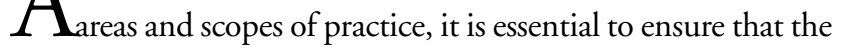
quality of services increases as well. It is also necessary to optimize services and judiciously allocate the limited resources available. To ensure high quality of care and optimization of pharmacy resources, measurable indicators are required to assess the baseline value of service and any enhancements gained as services are reallocated or expanded. Given that pharmacist services in inpatient care areas include interactions with and education of patients, patients' feedback and ratings can be used to evaluate their perception of the value of these services. In previous studies, patients valued pharmacists most when they provided information about drug-drug interactions, drug-food interactions, and medication administration.

At the time of the current study, in mid-2007, the former Calgary Health Region (now part of Alberta Health Services) had 2425 acute care beds in its 4 acute care centres within the city of Calgary: Alberta Children's Hospital (125 beds), Foothills Medical Centre (1300 beds), Peter Lougheed Centre (500 beds), and Rockyview General Hospital (500 beds). At the time of the study, the institution employed 135 pharmacists who were assigned to more than 50 patient care areas, for both inpatients and outpatients. Pharmacy services for the Calgary centres were regionalized, and pharmacists were assigned to areas that were admitting and treating patients with complex and high-risk medication needs. The inpatient areas to which pharmacists were assigned included intensive care units, acute medicine, geriatrics, pediatrics, transplant care, high-risk surgery, oncology, and psychiatry.

At the time of the study, pharmacists within the former Calgary Health Region were evaluating clinical pharmacy services and were planning strategically to ensure directed and rational enhancements to those services for the future. As part of these improvements, they established "SMART" (specific, measurable, attainable, reasonable, and time-based ${ }^{2}$ ) objectives to guide the assessment and enhancement of patient care services. The following objective for clinical pharmacy services appeared in the strategic plan: "By 2010, 50\% of Calgary Health Region complex and high risk patients surveyed will recall seeing a pharmacist in hospital post discharge". To measure progress toward this objective, the department wanted to establish the baseline frequency of patients who recalled seeing a pharmacist during their hospital stay. As the department implements new programs, new models of practice, and clinical competencies for pharmacists, the percentage of patients who recall interacting with a pharmacist is expected to increase. Other hospital pharmacies have used a similar before-and-after survey method to determine the value of new education programs. ${ }^{3}$

This study was designed to answer 2 questions: Among patients in the Calgary Health Region who have complex and high-risk medication needs, what is the baseline percentage who recall speaking to a pharmacist during their hospital stay when surveyed shortly after discharge? What is their reported satisfaction with those interactions?

\section{METHODS}

This study had a retrospective cross-sectional or prevalence design. The study was a telephone survey of acute care patients who had been discharged from hospitals within the former Calgary Health Region during June 2007. The primary outcome was the proportion of patients who recalled an interaction with a pharmacist on the unit where they were treated. The secondary outcome, for those patients who recalled seeing a pharmacist during their hospital stay, was satisfaction with the interaction with the pharmacist. The number of patients required for this survey was calculated using Bayesian sample size determination. ${ }^{4}$ To detect an estimated prevalence of $50 \%$, 384 survey respondents were needed. Discharges from the former Calgary Health Region facilities totalled over 1000 patients per month at the time of the study. Therefore, a list of patients discharged from all 4 Calgary acute care hospitals over a 1-month period (June 1 to June 30, 2007 inclusive) was requested from the Quality Safety and Health Information department. Potential privacy concerns were brought forward to the Information and Privacy Office of the former Calgary Health Region, which confirmed that there were no issues.

The following exclusion criteria were applied: length of stay less than $24 \mathrm{~h}$; death, discharge to a long-term care facility, or transfer to another acute care unit or facility; discharge from any of the region's obstetrics units; and discharge from a surgical unit other than transplant, cardiology, or vascular surgery units. In terms of pharmacist coverage on surgical units, priority has been given to units treating high-risk patients needing complex care, such as transplant, cardiology, and vascular surgery units. At the time of this study, no other surgical units in these facilities had been assigned pharmacist coverage.

Patients were randomly selected from the list, and 2 thirdyear pharmacy students (including L.I.) conducted the standardized survey by telephone. Data on the patient's name, age, sex, personal health care number, treatment unit, and hospital were gathered from the list of discharged patients. Two types of data were collected directly from the patients: whether they recalled speaking with a pharmacist and their overall satisfaction with this interaction, on a scale from 1 to 5 , where $1=$ very dissatisfied and $5=$ very satisfied. For patients under 18 years of age and those who could not answer the survey because of physical reasons preventing speech, another person, such as a family member or caregiver, was asked to answer the questions with the patient's consent. At 3 of the 4 sites (Alberta Children's Hospital, Peter Lougheed Centre, and 
Table 1. Age and Sex of Patients Who Participated in Telephone Survey

\begin{tabular}{lrr} 
Characteristic & \multicolumn{2}{c}{$\begin{array}{c}\text { No. (\%) of Respondents } \\
(\boldsymbol{n}=\mathbf{3 9 7})\end{array}$} \\
\hline Sex & 214 & $(53.9)$ \\
Male & 183 & $(46.1)$ \\
Female & & \\
\hline Age (years) & 42 & $(10.6)$ \\
$0-17$ & 22 & $(5.5)$ \\
$18-30$ & 37 & $(9.3)$ \\
$31-45$ & 41 & $(10.3)$ \\
$46-55$ & 60 & $(15.1)$ \\
$56-65$ & 80 & $(20.2)$ \\
$66-75$ & 115 & $(29.0)$ \\
\hline 75 & & \\
\hline
\end{tabular}

\section{Table 2. Distribution of Patients Who Participated in the Survey According to Acute Care Site}

\begin{tabular}{lcccc} 
Site & $\begin{array}{c}\text { No. (\%) of Patients } \\
\text { Participating in Telephone } \\
\text { Survey }(\boldsymbol{n}=\mathbf{3 9 7})\end{array}$ & \multicolumn{2}{c}{$\begin{array}{c}\text { No. (\%) of Total Beds } \\
\text { in Calgary } \\
\text { Health Region }\end{array}$} \\
\hline Alberta Children's Hospital & 32 & $(8.1)$ & 125 & $(5.2)$ \\
Foothills Medical Centre & 157 & $(39.5)$ & 1300 & $(53.6)$ \\
Peter Lougheed Centre & 110 & $(27.7)$ & 500 & $(20.6)$ \\
Rockyview General Hospital & 98 & $(24.7)$ & 500 & $(20.6)$ \\
\hline
\end{tabular}

Rockyview General Hospital), individual patients' recall of interactions with a pharmacist was cross-referenced with interventions by pharmacists that were documented for each patient, to assess the reliability of the data collected from the patients. At the time of the survey, intervention data were not tracked consistently by pharmacists at the Foothills Medical Centre.

\section{RESULTS}

Of the 5187 patients on the list provided by the Quality Safety and Health Information department, 1200 were randomly selected and contacted about participating in the survey. Of these 1200 patients, $400(33 \%)$ were available and agreed to take part in the study. After the survey was conducted, 3 of the respondents were excluded because it was discovered that they fell within certain of the specified exclusion criteria.

The average age of the 365 patients who had been discharged from the 3 sites serving primarily adult patients was 63 years, and 197 (54.0\%) of these respondents were male. The average age of the 32 patients who had been discharged from the Alberta Children's Hospital (a pediatric hospital) was 6 years, and $17(53 \%)$ of these patients were male (Table 1). The proportion of participants from each hospital reflected the distribution of beds in the former Calgary Health Region (Table 2).

Of the 397 respondents, 83 (20.9\%) recalled speaking with a pharmacist during their last stay in the hospital (Figure 1). Among these patients, the average satisfaction rating for pharmacy services was 4.4 out of 5, and 69 patients (83\%) rated the pharmacist interaction as at least 4 out of 5 (Table 3 ). Because site 1 was a pediatric hospital, all 32 responses for patients discharged from this site ( $8.1 \%$ of the 397 responses) were delivered by a proxy.

When patients' recall of interactions with a pharmacist was cross-referenced with pharmacist interventions documented for the patients, there was an overall correlation of $68 \%$ (Table 4).

\section{DISCUSSION}

In this survey study, patients' satisfaction was used to assess the value of pharmacist services provided at the former Calgary Health Region, as rated by patients. The results of this survey can be used as a baseline against which to compare the results of future surveys.

A potential limitation of this study is response bias, given that many patients $(67 \%$ of the original randomly selected sample) declined or were unavailable to participate. Other potential limitations include the unknown accuracy with which patients recalled seeing a pharmacist during their last stay in hospital. The survey was conducted 2 months after discharge, and some patients might have had difficulty recalling an interaction that far in the past. Recall might also have been poorer among patients who were very sick during their hospital stay. For those who had a proxy answer the survey for them, miscommunication or confusion might have affected the response. For some patients, pharmacists may have implemented inter- 


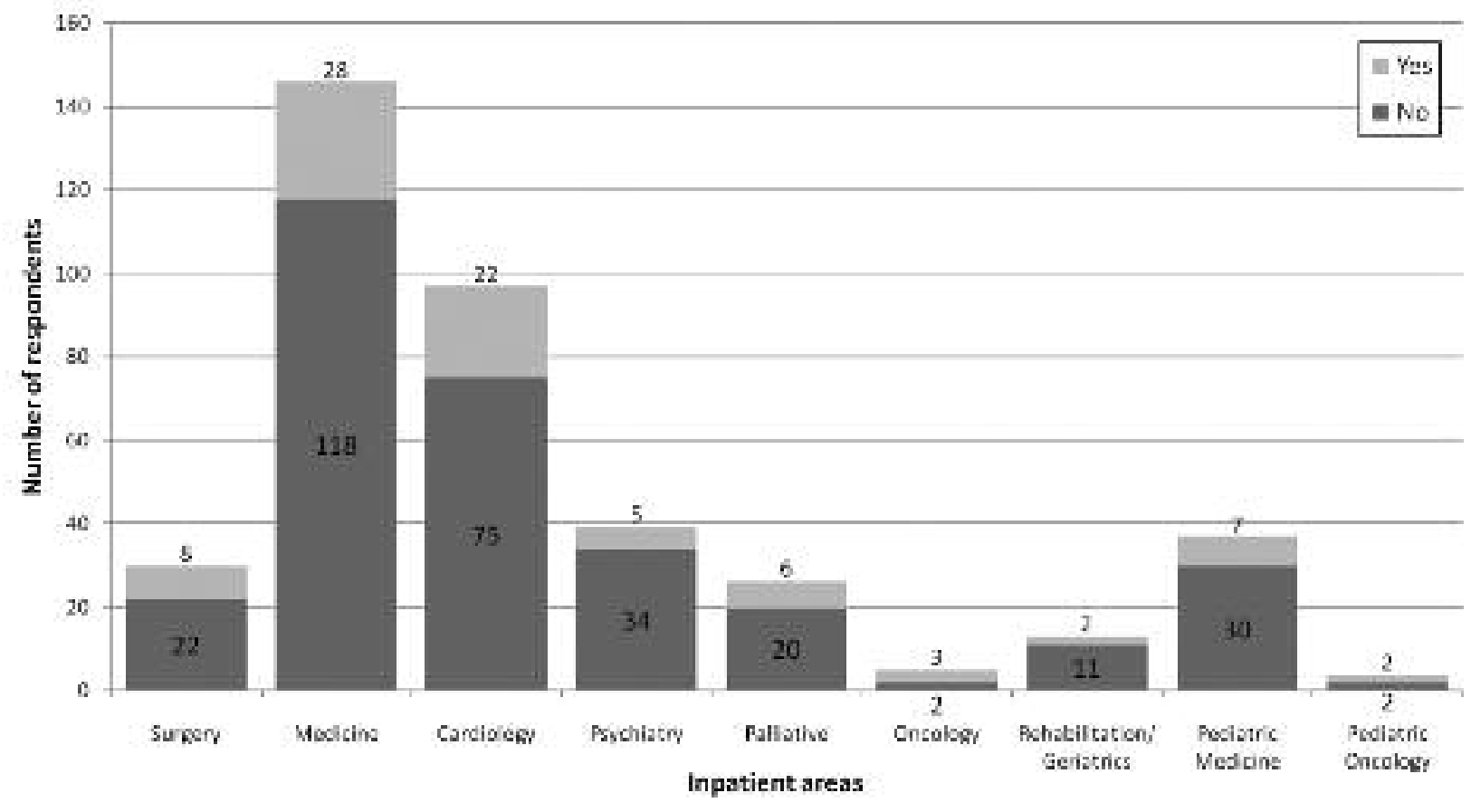

Figure 1. Number of patients who recalled speaking with a pharmacist by inpatient area.

Table 3. Distribution of Ratings of Pharmacist Interactions

\begin{tabular}{lc} 
Rating* & No. of Respondents \\
\hline 1 & 2 \\
2 & 1 \\
3 & 11 \\
4 & 20 \\
5 & 49 \\
Total & 83 \\
\hline
\end{tabular}

${ }^{* 1}=$ very dissatisfied, $5=$ very satisfied.

Table 4. Correlation Between Patient Recall and Pharmacist-Recorded Interventions

\begin{tabular}{lccc} 
Site & $\begin{array}{c}\text { No. of Patients Recalling } \\
\text { Interaction with } \\
\text { Pharmacist }\end{array}$ & $\begin{array}{c}\text { No. (\%) of Pharmacist } \\
\text { Interventions } \\
\text { Recorded }\end{array}$ \\
\hline Alberta Children's Hospital & 8 & 4 & $(50)$ \\
Peter Lougheed Centre & 20 & 14 & $(70)$ \\
Rockyview General Hospital & 25 & 18 & $(72)$ \\
Overall & 53 & 36 & $(68)$ \\
\hline
\end{tabular}

ventions without speaking directly to the patient. Some patients who were admitted to hospital frequently could not remember whether they saw the pharmacist during the last visit or during a previous visit. A few patients might have confused nurses with pharmacists, since many nurses provide medication counselling. For example, in one study, about $45 \%$ of patients received counselling from nurses and $43 \%$ from doctors. ${ }^{5}$ To verify whether this bias was a significant concern, we cross-referenced interactions with pharmacists that were recalled by survey respondents with recorded pharmacist interventions for 3 of the 4 sites. Among the 3 sites with correlating patient intervention data, the majority of instances of patient recall of an interaction corresponded with a recorded pharmacist intervention (68\%). Another limitation of our study is that even where patient intervention data were documented consistently, it was still impossible to guarantee that all interactions were recorded. 
Furthermore, at one site, the Foothills Medical Centre, interactions were recorded too infrequently to measure; this site represented more than half of the former Calgary Health Region's total bed count.

Now that the baseline prevalence of patient recall of interactions with pharmacists has been established, the organization intends to conduct a similar survey annually. It is hoped that these surveys will reveal progress toward the goal of $50 \%$ recall, and attainment of that goal by 2010 . These results can be used as a baseline comparator for the assessment of new programs that may be initiated in the future. They can also be used by patient care managers working in the organization's pharmacy department to identify areas for improvement and to assist in following the progress of pharmacists toward the goal of increased interaction with hospital inpatients. Other regions may conduct similar surveys to assess the value of the care provided to patients. Future research could include more detailed surveys to evaluate patients' expectations of and knowledge about pharmacy services. This study focused on higher-risk care units, but it might also be useful to specifically identify and survey high-risk patients, rather than randomly selected patients from particular units.

In conclusion, the former Calgary Health Region was encouraged that the baseline proportion of patients who remembered interacting with one of the hospital's pharmacists was as high as $21 \%$. These results have motivated the region to expand this type of pharmacy service "spot check" in the future, as it strives to enhance the quality of pharmacy clinical services provided to patients.

\section{References}

1. Polyak BA, Katz LA, Szela J. Evaluation of patient satisfaction with the initiation of clinical pharmacy services in an HIV clinic. In: ASHP 33rd Midyear Clinical Meeting; 1998 Dec; Atlanta (GA). page P-372(E).

2. Doran GT. There's a S.M.A.R.T. way to write management goals and objectives. Manag Rev (AMA Forum) 1981;70(11):35-36.

3. Young EN, Bishop HA, Peters BN. Improving patient satisfaction through inpatient pharmacy education services in a 60-bed cardiovascular hospital. In: ASHP 38th Midyear Clinical Meeting; 2003 Dec; New Orleans (LA). page $\mathrm{P}-611(\mathrm{E})$.

4. Herring $\mathrm{AH}$, Yang J. Bayesian modeling of multiple episode occurrence and severity with a terminating event. Biometrics 2007;63(2):381-388.

5. Meyer LS, Tran JH. Patient satisfaction survey. ASHP 30th Midyear Clinical Meeting; 1995 Dec; Las Vegas (NV). page P-20(E).

Lori Romonko Slack, BSP, PharmD, is a Pharmacy Patient Care Manager, Practice Leadership, with Alberta Health Services, Rockyview Hospital Site, Calgary, Alberta.

Lesley Ing was, at the time this study was conducted, a third-year pharmacy student at the University of Alberta. She is now with the Pharmacy, Alberta Health Services, Calgary, Alberta.

\section{Address correspondence to:}

Dr Lori Romonko Slack

Pharmacy Patient Care Manager, Practice Leadership

Alberta Health Services, Calgary

Rockyview Hospital Site

7007 14th Street SW

Calgary $A B$

T2V $1 \mathrm{Pg}$

e-mail: lori.romonko-slack@albertahealthservices.ca

Acknowledgement

The authors thank Kyle Fisher, third-year pharmacy student at the University of Alberta, for assistance with the telephone interviews. 